\title{
Procedimiento administrativo y acceso a la justicia de los accidentes y enfermedades del trabajo. A propósito de la sanción de la Ley 27.348 Complementaria de Riesgos del Trabajo ${ }^{1}$
}

Administrative procedure and access to justice in occupational accidents and diseases. With regard to the law 27.348 complimentary of work risks

Procedimento administrativo Acidente de trabalho. Doença ocupacional

Procédure administrative et accès à la justice pour les accidents et les maladies liés au travail. Á propos de la sanction de la loi 27.348 Complémentaire Risque de Travail

\section{Gastón Valente ${ }^{2}$ Universidad Nacional de La Plata}

Revista Derechos en Acción / ISSN 2525-1678 / e-ISSN 2525-1686

Año 4/Nº 10 Verano 2018/2019 (21 diciembre a 21 marzo), 326-362

DOI: https://doi.org/10.24215/25251678e256

ORCID: https://orcid.org/0000-0002-7575-1568

Recibido: 17/02/2019

Aprobado: 01/03/2019

Resumen: En Argentina las primeras normas sobre reparación de los accidentes y enfermedades del trabajo, se instrumentaron a partir de procedimientos administrativos. El proceso judicial especial surgiría muchos años más tarde, y se constituiría entonces como el gran instrumento de efectivización de derechos para los trabajadores accidentados,

\footnotetext{
1 Ponencia presentada en XLIV Jornadas de Derecho Laboral de la Asociación de Abogados Laboralistas 22, 23 y 24 de noviembre de 2018 Mar del Plata.

2 Abogado, Facultad de Ciencias Jurídicas y Sociales de la Universidad Nacional de La Plata (2000), especialista en Derecho Laboral y Asesor sindical.
} 
fundamentalmente a partir de creaciones pretorianas, como lo fueron el accidente in itinere y la enfermedad - accidente, reconociendo cobertura allí donde la ley lo negaba. Ahora bien, ¿por qué el procedimiento administrativo para los trámites de los accidentes y enfermedades del trabajo, pasó de ser la única herramienta de los trabajadores; para ser utilizado ahora como, el gran instrumento de limitación al proceso y al acceso a la justicia?

Palabras claves: procedimiento administrativo. Accidente de trabajo. Enfermedad laboral.

Abstract: In Argentina, the first rules about occupational accidents and diseases reparation, were established through administrative procedures. The special judiciary procedure would appear many years later, as the biggest tool to make the workers' rights effective, fundamentally through praetorian creations, such as the accident in itinere and the occupational disease, recognizing reparations where the law denied it. And so, Why is it that the administrative procedure for occupational accidents and diseases went from being the only workers' resource, to become the greatest instrument to confine the process and the access to justice?

Keywords: Administrative Procedure. Work accident. Occupational disease.

Resumo: Na Argentina, as primeiras normas sobre reparação dos acidentes e doenças do trabalho foram instrumentadas a partir de procedimentos administrativos. 0 processo judicial especial surgiria muitos anos depois, e se constituiria então como o grande instrumento de efetivação dos direitos pelos trabalhadores lesionados, fundamentalmente a partir de criações pretorianas, como foram 0 acidente in itinere e a doença - acidente, reconhecendo cobertura onde a lei o negava. Agora bem, por que o procedimento administrativo para os trâmites dos acidentes e doenças do trabalho passou de ser a única ferramenta dos trabalhadores; para ser usado agora como o grande instrumento de limitação ao processo e ao acesso à justiça?

Palavras-chave: Procedimento administrativo Acidente de trabalho. Doença ocupacional

Résumé: En Argentine, les premiers règlements sur la réparation des accidents et des maladies professionnelles ont été instrumentés sur la base de procédures administratives. Le processus judiciaire spécial 
se présente quelques années plus tard, comme le grand instrument d'effectuation des droits des travailleurs blessés, essentiellement partant de créations prétoriennes, comme làccident " in itinere " et la «maladie-accident, y reconnaissant une couverture où la loi l'avait nié. Alors ¿pourquoi la procédure administrative pour les procédures des accidents et des maladies du travail, devenue le seul outil des travailleurs, est-elle utilisée maintenant comme le grand instrument de limitation de l'accès à la justice?

Mot-clés: Procédure administrative. Accident de travail. Maladie professionnelle.

\section{Introducción}

En Argentina las primeras normas sobre reparación de los accidentes y enfermedades del trabajo, se instrumentaron a partir de procedimientos administrativos. El proceso judicial especial surgiría muchos años más tarde, y se constituiría entonces como el gran instrumento de efectivización de derechos para los trabajadores accidentados, fundamentalmente a partir de creaciones pretorianas, como lo fueron el accidente in itinere y la enfermedad - accidente, reconociendo cobertura allí donde la ley lo negaba.

Ahora bien, ¿por qué el procedimiento administrativo para los trámites de los accidentes y enfermedades del trabajo, pasó de ser la única herramienta de los trabajadores; para ser utilizado ahora como, el gran instrumento de limitación al proceso y al acceso a la justicia?

Claro está que para poder entender esta mutación histórica del procedimiento administrativo y de la limitación al acceso a la justicia, debemos hacer un somero análisis de la evolución de éste instituto, para llegar así al nuevo diseño normativo de la ley 27.348, y la imposición del agotamiento previo, obligatorio y excluyente de la vía administrativa.

El diseño administrativo originario de la ley 24.557, luego de la desarticulación sufrida por las reiteradas declaraciones de 
inconstitucionalidades, resurge ahora con nuevos condimentos a partir de la reforma de la ley 27.348 , que no son ingeniosos, sino que utiliza viejos institutos del Derecho Administrativo, que sirvieron en una época y en dicha rama del derecho, para la limitación de la demandabilidad del Estado. Los operadores e intermediarios del sistema imitan así, cierta inmunidad judicial que otrora tenían los Estados. ${ }^{3}$

Por eso consideramos que el nuevo procedimiento administrativo de la ley 27.348, tiene sólo una vocación limitante del acceso a la justicia de los trabajadores accidentados, de acuerdo al pregonado fin político de la reforma, que era la reducción de la litigiosidad. Resultando entonces, una ley regresiva en el ámbito del Derecho Laboral, que contradice principios humanistas y vulnera elementales garantías procedimentales, como lo son el debido proceso y la tutela administrativa efectiva.

En ése sentido trataremos de abordar en nuestro análisis, la incorporación de institutos propios del Derecho Administrativo, como el agotamiento de la vía administrativa, los plazos de caducidad, la cosa juzgada administrativa, y el recurso judicial suficiente. También analizaremos, como cierto sector de la jurisprudencia avala ésta reforma, a partir de sustentar una ya perimida "tesis de la subsanación", que significa que, no importa cuán grado de vulneración de derechos pueda existir en el procedimiento administrativo ante Comisiones Médicas, si al final del mismo existe un recurso judicial suficiente, para "subsanar" o "convalidar" lo previamente actuado en sede administrativa.

Esto, sin lugar a dudas, encorseta a la Justicia Laboral, y le asigna un mero carácter revisor de lo actuado previamente por la Administración. Resignándose así, las funciones constitucionales de poder jurisdiccional, y violando nuestra constitución y su sistema "judicialista" de resolución de conflictos.

3 Esto es lo que expuse en representación de la CTA de los Trabajadores en el debate de la Ley 27.348 en la Comisión de Trabajo y Previsión en el Senado de la Nación, ver versión taquigráfica del día 23/11/2016 página 16/18. 
Finalmente trataremos de demostrar, que en el procedimiento administrativo de la ley 27.348, deben regir las reglas del debido proceso y la tutela administrativa efectiva. Como así también, que si no se cumplen ésas garantías mínimas, el procedimiento no puede quedar subsanado con un recurso judicial ulterior, como lo ha expresado cierto sector de la jurisprudencia; ello vulneraría la jurisprudencia vigente de la Corte Suprema de Justicia de la Nación (CSJN), la doctrina legal de la Suprema Corte de la Provincia de Buenos Aires (SCBA) y los estándares establecidos por la Corte Interamericana de Derechos Humanos (Corte IDH).

\section{Antecedentes del procesamiento administrativo de los accidentes y enfermedades del trabajo}

Señala Cornaglia ${ }^{4}$ que la primer ley especial de reparación para accidentes y enfermedades del trabajo, fue la ley 9.085 de 1913 (Indemnización por accidentes de trabajo a obreros del Estado), a partir de un lamentable accidente. Es anterior a la ley 9.688, y constituyó una norma propia del derecho administrativo laboral, que facultaba al poder administrador (y le ordenaba con timidez), "entregar" a las víctimas futuras de hechos similares, el monto de una tarifa para el valor vida y baremo para las incapacidades que reconoció. Fue un ejercicio displicente de un poder soberano dice el autor. Pero la podemos sindicar como la primera ley de procesamiento administrativo de los infortunios laborales en Argentina.

Desde sus orígenes, la CSJN nunca exigió ningún trámite administrativo previo para el acceso a la justicia de los trabajadores accidentados. Ello lo expresó a partir del fallo "Monreal de Lara de Hurtado c. La Nación" . Esta fue una sentencia fundacional en el reconocimiento de la responsabilidad por la actividad riesgosa, que no requieren existencia de conducta culposa en

4 Ver "Una Ley olvidada." Por Ricardo J. Cornaglia. Número XXI (Julio 2018) de ladefensa.com.ar

5 Fallos CSJN T CXXIV, p. 329. 1916 
lo dañantes, en la cual se planteó el debate si era necesaria pedir la venia legislativa previa que existía en aquel entonces (por ley 3.952), para demandar al Estado empleador. La Corte diría que ello no era necesario, porque el Estado actuaba como empleador, no en el ejercicio del Poder Público. Superándose así uno de los primeros valladares que existían en la época al acceso a la justicia.

Ya a partir de sancionada la ley 9.688 en 1.916, todos los autores coincidirían que era una ley de trámite eminentemente judicial $^{6}$, pero el Poder Ejecutivo reglamentó vía decretos los trámites administrativos, los que para algunos autores constituyó un evidente exceso reglamentario ${ }^{7}$.

Unos años más tarde, la Provincia de Buenos Aires ya contaba con la ley 4.548 que reglamentó el Departamento Provincial de Trabajo, en la cual se regulaba el procedimiento administrativo para el reclamo de la indemnización por accidentes de trabajo de la Ley $\mathrm{N}^{\circ}$ 9.688. Esta norma exigía, previo al reclamo judicial, un certificado en donde constase que el empleador había negado la indemnización ante la instancia del Departamento de Trabajo. Esta norma fue cuestionada, pero la Corte consideró que la Ley $\mathrm{N}^{\circ} 9.688$ contenía disposiciones de fondo, que formaban parte del Cód. Civ., pero que el Congreso

6 "La lectura del texto de la ley dejó siempre en nuestro espíritu el convencimiento de que sus autores no tuvieron el propósito de hacer una ley reglamentaria de condiciones de trabajo, sino una ley declarativa de derechos. No tuvieron la intención, pues de que ella se moviera en lo fundamental en la esfera de lo administrativo, sino en los estrados del poder judicial." (ver Alejandro M. Unsain en "La Gestión Administrativa en la Ley de Accidentes" en Derecho del Trabajo, año 1945 tomo V, página 351 y ss.)

7 "No está por la ley facultada la autoridad administrativa para ordenar que un patrón indemnice como accidente un suceso que a su juicio no lo es o cuando estima que el hecho se ha producido por culpa grave o que su actividad no es de las contempladas en la ley o cuando niega la existencia de vínculo contractual con la víctima, etc. Lo que el órgano administrativo necesariamente tiene a su cargo, es la parte que a los hechos se refiere: constatación de los antecedentes del caso, corrección del acta de denuncia, inspección "in situ", verificación del salario, control de la prestación de asistencia médica y farmacéutica, determinación de incapacidades, etc. En otros términos: a la administración los hechos y al juez el derecho. Creemos que es la buena doctrina." (ver Alejandro M. Unsain ob. cit.) 
no pretendió legislar sobre el procedimiento que cada provincia podía establecer. Por otra parte, el procedimiento administrativo ante el Departamento Provincial del Trabajo, no era objetable pues siempre existía la etapa judicial. El paso administrativo sólo tendía a lograr mayor rapidez y abaratar la gestión de los intereses obreros, según resolvieron los cortesanos ${ }^{8}$.

Ya en 1944, se dicta el Decreto Ley 21.425 que estableció una instancia administrativa obligatoria para el resarcimiento de los accidentes del trabajo ocurridos en el territorio de la Nación. Esta ley fue contemporánea a la creación por decreto, del Fuero Nacional del Trabajo, por lo que tuvo una muy corta vida. Imponía la obligatoriedad de la intervención administrativa para todos los accidentes de trabajo de jurisdicción nacional, por intermedio de la Dirección de Trabajo, de la flamante Secretaría de Trabajo y Previsión cuyo secretario era Juan D. Perón. La doctrina especializada de la época le salió al cruce al manifestar que "Al acordarse facultades de "jueces de derecho" a las autoridades del trabajo, se rompe el criterio de la división de poderes que informa la Constitución nacional"9.

Con la consagración legislativa del fuero del trabajo, unos años más tarde, a través de la ley 12.948 en el ámbito nacional, y la ley 5.178 en territorio bonaerense, ambas jurisdicciones tomaron caminos diferentes. Mientras que en Nación se dictaba el Decreto 1.005 de 1.949, que establecían un trámite administrativo previo al acceso a la justicia a través de las Cámaras de Conciliación y Arbitraje; en Provincia de Buenos Aires se habían organizado los tribunales de trabajo en donde no se preveía un procedimiento

\footnotetext{
8 Ver "Antonio Costes c/Andrés Prado" del 19 de junio de 1940, en Fallos 187:83; también "Blas Freijomil c/Cía. de Seguros La Nueva Zelandia" del 24 de febrero de 1943, en Fallos 195:50; se sigue la misma doctrina en Fallos 195:529 y en Fallos 201:135. (citado Tanzi, Héctor J. en “Historia Ideológica de la Corte Suprema de Justicia de la Nación (1930-1947) en Revista lusHistoria - Número 1 (2005)

9 Véase Luis A. Depontín en Derecho del Trabajo, año 1945 tomo V, página 215, Alejandro M. Unsain, en Derecho del Trabajo, año 1945 tomo V, página 351 y ss., J. D. Ramírez Gronda, en Derecho del Trabajo, año 1942 página 58 y ss., y Carlos R. Desmarás, en Rev. La Ley tomo 20 página 380
} 
de instancia inicial administrativo. Es más, se derogó la parte de la ley 4.548 que otorgaba funciones jurisdiccionales a la Secretaría de Trabajo y Previsión en ámbito provincial, por lo que no se requería dar intervención previa obligatoria en los casos de accidentes a órganos administrativos. Al igual que Buenos Aires, pocas provincias siguieron el modelo porteño de incluir una instancia como necesaria y obligatoria previa al proceso judicial, y si lo hicieron, no lo delegaron en un organismo administrativo ${ }^{10}$.

El Decreto 1.005 reglamentando el artículo 5 de la Ley 12.948, establecía los trámites administrativos que correspondían por las denuncias de accidentes de trabajo, que implicaban además, asesoramiento a las víctimas y sus familiares, y en caso de que no se aceptare la liquidación por la cual se culminaba el procedimiento, se debían remitir las actuaciones a la Sección Accidentes del Trabajo del Instituto Nacional de Previsión Social a los efectos de los artículos 9 y 10 de la ley 9.688 esto es, para su cobro y depósito en la Caja de Garantía de la ley de accidentes $^{11}$. Es importante ver las diferencias que existen con el régimen administrativo actual, en donde, ante el vencimiento de los plazos o desinterés del trabajador o su derechohabiente, ahora se pierde el derecho, antes los funcionarios del ministerio debían continuar la acción para su cobro e ingreso de los fondos en la Caja de Garantía.

Los primeros fallos judiciales, no convalidaron ninguna restricción al acceso a la justicia que imponían estas normas reglamentarias. Los más alineados al gobierno de turno decían que a pesar de las buenas voluntades que pudiera expresar la norma, al poner al Estado al servicio del asesoramiento y cobro de las indemnizaciones de los trabajadores, era inconstitucional. Los más enfrentados, entre los que se encontraba cierto sector disidente y gran parte del Poder Judicial tradicional que veía con malos ojos el ejercicio de funciones propias por parte de órganos administrativos, la invalidaron rápidamente.

10 Ver Juan Manuel Palacio “La Justicia Peronista” Siglo XXI 2018

11 Ver Código del Trabajo anotado Krotoschin y Ratti editorial Depalma, página 364 
En un fallo plenario la Cámara de Paz Letrada de la Capital Federal ${ }^{12}$, permitía igualmente el acceso a la vía judicial, incluso con acuerdos firmados, cuando había dicho que "La indemnización establecida por el Dep. Nac. Del Trabajo y aceptada por el obrero, no priva a éste del derecho para reclamar ante la justicia una mayor indemnización". La jurisprudencia laboral en un principio había sido dubitativa, por ejemplo cuando resolvió que "cuando las partes se someten voluntariamente al decr. 1055/49, las decisiones adoptadas causan instancia y son irrevisables por la vía de acción judicial"13. Pero finalmente esta postura de no apertura judicial se dejaría de lado en un fallo plenario laboral, cuando se dijo que: "La opción del trabajador accidentado por el trámite administrativo previsto por el decr. 1005/49, y el dictado de la resolución respectiva, no obsta a que se demande originariamente ante la justicia nacional del trabajo, para revisar la incapacidad allí fijada" ${ }^{14}$.

Al igual que la Justicia de Paz Letrada de la Capital Federal, la Corte que había creado la "doctrina de facto" y se había negado a tomar juramento a los primeros jueces de la Cámara Laboral; esta vez con sentido "republicano", invalidaba el órgano por el cual se procesaban administrativamente los reclamos laborales en el interior del país. Ello en tanto a días de las elecciones presidenciales, declaraba la inconstitucionalidad del Decreto de Facto 15.074 de creación de la Secretaría de Trabajo y Previsión; allí dijo que con la absorción por parte del Estado Nacional de las secretarías de trabajo provinciales se ha "derogado una ley provincial, ha transformado el organismo provincial en nacional y atribuido a una entidad nacional jurisdicción para conocer en territorio de las provincias sobre cuestiones regidas por la legislación de fondo. La violación de

\footnotetext{
12 Cámara de Paz Letrada Capital Federal (en pleno) 6/07/45 “Szesza, Juan c/ La Comercial de Rosario (Cía de Seguros) Derecho del Trabajo año 1945 Tomo V página 351

13 CNTrab., 3ㅜ, 30/04/51, Fallos 11-292, ídem $2^{\circ}$ 20/2/70, LT 1970-461

14 CNTrab., en pleno, 19/8/74, LL 156-482. DT 1974-974. LT 1974-1039. DT 1974-667
} 
los principios constitucionales citados es patente. Ni el Congreso nacional hubiera podido hacerlo"15

Llegamos así a "Fernández Arias c/ Poggio"16. Con una Corte con nuevos integrantes, consecuencia del golpe de 1955, y que ya había insinuado el tema en otro precedente sobre la potestad de la Justicia de revisar lo previamente resuelto en sede administrativa ${ }^{17}$. Si bien en este caso, no refiere la Corte a la tramitación administrativa de accidentes laborales, es de fundamentalmente importancia la sentencia, en tanto se aborda el tema del "control judicial suficiente" de lo actuado en sede administrativa en un supuesto de controversia entre privados. Se trataba el caso, de un conflicto suscitado en el ámbito de las Cámaras de Aparcerías Rurales, las que constituían verdaderos tribunales administrativos, los que resolvían conflictos entre privados (como era el caso de los desalojos de los tamberos medieros, etc.), y que aun agotando la vía administrativa, no se preveía un recurso judicial suficiente. La Corte fue contundente a partir de éste precedente, al admitir que la atribución de funciones jurisdiccionales a entes administrativos para dirimir controversias de naturaleza patrimonial entre particulares implica un doble quebrantamiento constitucional ya que si, por una parte, produce la transgresión

\footnotetext{
15 Fallos 204-1946 “Cía Dock Sud” 1/02/1946 (ampliar Juan Manuel Palacio ob cit)

16 Fallos 247:646, 19/09/1960

17 Fallos 244:548 "López de Reyes c/INSTITUTO NACIONAL DE PREVISIÓN SOCIAL"1959 allí se dijo: "la revisión por los jueces no puede entonces quedar reducida... al aspecto que se vincula con la correcta aplicación de las normas jurídicas por el organismo administrativo, sino que, teniendo en cuenta que los procesos judiciales se integran, al menos en una instancia, con la faz 'de hecho' y con la 'de derecho', esa revisión ha de penetrar el examen de los hechos, aspecto esencial que no puede ventilarse solamente en la órbita administrativa sin que los principios precedentemente expuestos quedasen transgredidos. Que si, como aconteció en esta causa, se dejare exclusivamente en manos de la Administración lo que concierne a la prueba de los hechos, todo agravio legítimo al respecto quedaría fuera del examen judicial, sin que el afiliado tuviese la oportunidad, entonces, de reclamar por la violación de sus derechos ante los órganos que la Constitución prevé a esos efectos. Y es fácil concluir que una indebida fijación de los hechos no puede ser subsanada con una acertada selección de normas jurídicas porque sería equivocado el presupuesto de que entonces se habría partido en el acto de juzgar"
} 
del principio que prohíbe al Poder Ejecutivo (y, por ende, a los órganos administrativos) el ejercicio de funciones judiciales (art. $109 \mathrm{CN}$ ) por la otra transgrede abiertamente la garantía de la defensa en juicio a la persona y sus derechos $(\text { art. } 18 \mathrm{CN})^{18}$. Por ello concluye la Corte que el ejercicio de facultades jurisdiccionales por órganos de la administración, debe estar necesariamente supeditada al control judicial suficiente.

Luego la historia de la evolución del procesamiento administrativo de los siniestros laborales es más conocida. Ya con la sanción de ley 24.557 en 1995, por la cual, utilizando las entonces creadas Comisiones Médicas del régimen previsional (artículo 51 de la ley 24.241), se crea un sistema de intervención de organismos administrativos destinado al procesamiento de los siniestros laborales. En su origen esta norma tenía ínsito todo el andamiaje de desactivación del acceso a la Justicia Laboral, al preverse la instancia administrativa sólo con una ulterior intervención de la competencia federal (art. 46 ley 24.557). Así el Decreto 717/96 pasaría a ser la regulación del procedimiento administrativo ante las Comisiones Médicas, a las que la ley le reconocería facultades cuasi jurisdiccionales en sus artículos 21 y 22, como lo son la de determinar la "naturaleza laboral del accidente o profesional de la enfermedad", el "carácter y grado de la incapacidad, y el "contenido y alcances de las prestaciones en especie". Este sistema de procesamiento administrativo de los siniestros, que sólo preveía el acceso directo a la justicia para el supuesto de dolo del empleador (art. 39 inc. 1), fue declarado inconstitucional por la CSJN a partir del precedente "Castillo, Á.S. c/ Cerámica Alberdi S.A." ${ }^{19}$ y subsiguientes.

Coincidimos con lo señalado por Juan Amestoy y Nicolás Menestrina $^{20}$ cuando refieren que paradójicamente la Corte

\footnotetext{
18 Ver "Las facultades jurisdiccionales de los entes reguladores (a propósito del caso "ángel Estrada")" por Juan Carlos Cassagne

19 Fallos: 327:3610 de 2004

20 En "Consideraciones relativas a la ley 27.348" Redea Derechos en Acción Año 2 n 3 otoño 2017.
} 
Federal nunca declaró frontalmente la inconstitucionalidad de los artículos 21 y 22 de la ley 24.557, ocupándose en forma tangencial del abordaje de la cuestión en "Obregón, Francisco Víctor c/Liberty ART"21, cuando resolvió que "la habilitación de los estrados provinciales a que su aplicación dé lugar no puede quedar condicionada o supeditada al previo cumplimiento de una vía administrativa ante "organismos de orden federal", como lo son las comisiones médicas previstas en los arts. 21 y 22 de la LRT". La SCBA de la Provincia de Buenos Aires ya había hecho lo propio, a partir de la causa "Quiroga"22.

Aún con éstos antecedentes el legislador insistió con el dictado de la Ley 27.348, fortaleciendo nuevamente la instancia administrativa previa, obligatoria y excluyente a toda actuación judicial. reglamentándolo a partir de la Resolución 298/2017.

\section{Una mirada desde el derecho administrativo. Evolución desde la indemandabilidad, hacia el reconocimiento del acceso a la justicia}

\section{III.1. Un sistema judicialista}

Dice Cassagne que cuando un sistema recibe el calificativo de judicialista se da por sobre entendido la circunstancia de que la calificación no se refiere al juzgamiento de las causas entre particulares (justicia civil, comercial, o penal), dado que éstas, en los países civilizados donde rige la división de poderes, se ventilan ante jueces, separados orgánicamente de los poderes ejecutivos, que gozan independencia frente a estos últimos. Continúa sosteniendo el autor que en la vereda opuesta de un sistema judicialista se encuentran los que instrumentan tribunales administrativos ${ }^{23}$.

21 Causa 0. 223. XLIV. Recurso de Hecho de 2012

22 Causa L. 75.708 de 2003

23 Ver "El acceso a la justicia administrativa" Ponencia del Seminario Internacional de Derecho Administrativo en Facultad de Derecho del año 2004 Juan Carlos Cassagne 
De más está decir que por imperio del artículo 109 de la Constitución Nacional, nuestro país se estructura sobre un sistema judicialista. De allí el desacierto que correctamente le apuntara la Dra. Diana Cañal en su voto en la causa "Herrera Carlos Rubén c/ ART Interacción" ${ }^{24}$, al referir del equívoco del Fiscal General ante la Cámara Nacional de Apelaciones del Trabajo, Eduardo Álvarez, en la causa "Burghi, Florencia Victoria c/ Swiss Medical ART S.A." 25 , al pretender aplicar precedentes de la Corte norteamericana, sistema distinto al nuestro en tanto no cuenta con un precepto citado como el artículo 109 que prohíbe al presidente de la nación ejercer funciones judiciales.

Así y todo a partir de "Fernández Arias" nuestro país se las ingenió para admitir tribunales con facultades jurisdiccionales. Ahora bien, el Estado ha ensayado diferentes estrategias jurídicas para mantener el principio soberano de indemandabilidad, lo que condicionó el acceso a la justicia de los administrados. Esto ahora es imitado por la ley 27.348 para limitar la demandabilidad de los responsables en los siniestros laborales y como estrategia para bajar la litigiosidad.

\section{III.2. El agotamiento de la vía administrativa y los conflictos entre privados}

La reclamación y/o agotamiento de la vía administrativa, fue el instituto que sobrevino en el plano del Derecho Administrativo, luego de la eliminación de la venia legislativa. Dice Cassagne que tanto la ley 3.952 como la ley 11.634 prescribieron en el orden nacional el requisito de la reclamación administrativa previa y su denegatoria de toda demanda judicial contra el Estado. ${ }^{26}$ En ése sentido, no se podía demandar directamente, sin previamente agotar la vía administrativa, y una vez conseguida la resolución final, comenzaban a correr los plazos

\footnotetext{
24 Sentencia del 10/10/2017 de la CNAT sala III

25 Sentencia del 3/058/2017 de la CNAT Sala II

26 Juan Carlos Cassagne ob cit
} 
de caducidad generalmente breves, los que una vez vencidos, tornaban caduco el derecho a demandar.

A partir de la ley 19.549 de procedimientos administrativos a nivel nacional, se generalizó la regla del agotamiento de la instancia administrativa, pero siempre claro está, referido a la impugnación de actos administrativos. Por eso llamó la atención el diseño del agotamiento de la vía administrativa de la ley 27.348, cuando la controversia que regula, se trata de conflictos entre privados y no ya del cuestionamiento de funciones administrativas del Estado.

También coincidimos con lo expresado por Amestoy y Menestrina $^{27}$, en cuanto a la ubicación del sistema de riesgos del trabajo en el ámbito de la seguridad social, en los términos establecidos por la Constitución Nacional (art. 14 bis), esto es, otorgado por el Estado; el que por haberse permitido la intermediación privada (inconstitucionalmente), en los términos regulados por la ley 24.557, no puede haber nunca cuestionamiento de la función administrativa en el otorgamiento de los beneficios de la seguridad social, porque siempre el conflicto se presenta entre trabajadores y aseguradoras privadas, o empleadores autoasegurados, y en el caso de ser el Estado, cuando éste actúa como empleador no lo hace en el ejercicio de la función administrativa, como ya lo había señalado la Corte primigeniamente en el fallo "Montreal de Lara de Hurtado" antes citado.

El procedimiento administrativo de la Resolución 298/2017, es un trámite que regula generalmente conflictos entre particulares, es decir que no hay en juego el ejercicio de funciones administrativas, con lo cual el agotamiento de la vía administrativa, se torna un requisito innecesario, que generalmente alarga sin sentido el trámite previo a la demanda, demorando consecuentemente los plazos para el trabajador accidentado. En ése sentido ni la propia Ley Procedimientos Administrativos, exige

27 Juan Amestoy y Nicolás Menestrina op cit 
el agotamiento de la vía administrativa, si se advierte "la ineficacia cierta del procedimiento, transformando el reclamo previo en un ritualismo inútil" (ver artículo 32 inc. "e" ley 19.549), ni mucho menos cuando se reclamen "daños y perjuicios" (ver artículo 32 inc. "d" ley 19.549), siendo esto doctrina legal vigente de la SCBA al reconocer la demandabilidad directa ante supuestos de responsabilidad del Estado y reclamo de daños y perjuicios $^{28}$. De allí también la inconsistencia de obligar al paso por el procedimiento de la ley 27.348 para el ejercicio de la opción del artículo 4 de la ley 26.773, aun cuando el trabajador decida la reclamación integral de los daños y perjuicios.

\section{III.3. El agotamiento de la vía administrativa no tiene raigambre constitucional y no puede afectar derechos fundamentales}

El agotamiento de la vía administrativa no surge de ningún texto de la Constitución Nacional. En la Provincia de Buenos Aires, sólo se contempla en los casos en que esté en juego "el ejercicio de funciones administrativas", para "los supuestos en que resulte obligatorio agotar la vía administrativa" (ver artículo 166 Constitución Provincial), por lo cual quedan fuera los conflictos entre privados, los que sólo están reservados a los tribunales de justicia (ver artículo 15 y 168 Constitución Provincial).

De allí la desafortunada argumentación en la sentencia "Burghi" cuando se refiere que "no existe norma constitucional alguna que prohíba los trámites administrativos"; claro que no están prohibidos, pero ante los nuevos paradigmas fijados a partir de la reforma constitucional de 1994 en la defensa de los Derechos Humanos, no puede limitarse un derecha básico de todo estado de derecho, como lo es el derecho de acceso irrestricto a la justicia, con una exigencia en muchos casos innecesaria y dilatoria como lo es el agotamiento de la vía

28 SCBA "Gaineddu" Res. 23-4-2003, causa B.64.553 
administrativa. Esto quiere decir que, puede válidamente existir un procedimiento administrativo que tenga por fin efectivizar derechos, pero en modo alguno, éste debe estar orientado a restringirlos, como pareciera ser el caso de la regulación establecida por la ley 27.348 .

Por ello decimos, que con la reforma introducida por la ley 27.348, se establecen verdaderos privilegios que otrora eran utilizado por los Estados, y que ahora le son reconocidos a compañías privadas, que intermedias en el otorgamiento de prestaciones a los trabajadores dañados. De allí su improcedencia y su inconveniencia en su mantenimiento.

\section{III.4. Se deja sin efecto la presunción de legitimidad y fuerza ejecutoria de los dictámenes administrativos}

Pero el perjuicio para los trabajadores es más grande, cuando en el trámite regulado por la Resolución 298/2017, incluso se dejan sin efectos características propias de los actos administrativos en el proceso de impugnación, como lo es la presunción de legitimidad y fuerza ejecutoria, que originariamente tenía regulada la ley 24.557. Esto es, sin importar la interposición de recursos, como puede ser por el propio obligado al pago (la ART), la prestación dineraria igualmente debía ser liquidada.

El principio de presunción de legitimidad y fuerza ejecutoria de los actos administrativos, es un principio basal del Derecho Administrativo y de toda actuación del Estado. La ley 24.557, con todas las críticas que se le efectuaron a la misma, por lo menos respetaba éste principio, al no suspender la ejecución de los dictámenes médicos que determinaban incapacidad (que eran verdaderos actos administrativos). Es decir, el principio en el Derecho Administrativo, es el de la no suspensión del acto ante la interposición de los recursos. Este principio se encuentre receptado en el artículo 12 de la ley 19.549, lo que es de toda lógica, mantener el efecto no suspensivo ante la interposición de recursos contra los actos administrativos que tengan ejecutoriedad, máxime cuando nos encontramos ante la obligación 
de abonar prestaciones dinerarias, irrenunciables y de carácter alimentario, en la cual el tiempo de su reconocimiento y efectivización, son primordiales.

Lamentablemente, esto no es respetado por el nuevo procedimiento administrativo regulado por Resolución 298/2017. Ello en tanto, si se presenta un recurso contra un dictamen que reconoce incapacidad, o contra un acto que cierra la vía administrativa, el acto se suspende hasta tanto sea resuelto el recurso en sede judicial.

\section{III.5. El agotamiento de la vía administrativa, como limitación al acceso a la justicia}

Venia legislativa, tribunales administrativos, reclamación administrativa previa, plazos de caducidad y "tesis de la subsanación"; son sólo alguno de los institutos que se sucedieron en el tiempo, y que operaron en el plano del Derecho Administrativo como instrumentos para limitar la demandabilidad del Estado. Ahora ésta técnica es copiada por el diseño procedimental de la ley 27.348, para limitar la litigiosidad de los siniestros laborales.

El Derecho Administrativo ha avanzado en la eliminación y/o reducción de éstos institutos, que limitaban injustificadamente el acceso a la justicia, fundamentalmente a partir de las reformas constitucionales que se sucedieron en nuestro país en el año 1994.

Por ejemplo como nos apunta Botassi ${ }^{29}$, los artículos 15 y 166 de la Constitución de la Provincia de Buenos Aires, al establecer como garantía expresa la tutela judicial efectiva y el acceso irrestricto a la justicia, redujeron el requisito del agotamiento de la vía administrativa a "los supuestos en que resulte obligatorio agotar la vía administrativa" según lo determine expresamente la ley. Se invierte el principio, de ser necesario el agotamiento administrativo en todos los casos, a sólo aquellos

29 Ver el "Acceso a la Justicia en el Proceso Bonaerense", en Revista Derecho y Ciencias Sociales. Abril 2012. No6 (Acceso a la Justicia). Pgs.38-52 Carlos A. Botassi 
que expresamente los determine la ley. Y yo le agregaría algo obvio pero es necesario recordar para nuestra disciplina, esto rige solo para cuando se encuentren en juego "el ejercicio de funciones administrativas".

Con lo cual, el agotamiento de la vía administrativa, solo será necesaria, cuando se encuentre en juego el cuestionamiento de las funciones administrativas del Estado, sino sólo es una limitación inconstitucional al acceso a la justicia.

\section{III.6. La caducidad de los plazos y su inconstitucionalidad}

En referencia a los plazos de caducidad que establece el procedimiento regulado por Resolución 298/2017, de 15 días para la interposición del recurso de apelación contra actos del servicio de homologación (art. 16); estos plazos de caducidad, sólo serían constitucionales, si no se afectara la tutela judicial efectiva, y sólo sirvieran para bloquear el acceso a la justicia del trabajador, con un breve plazo, mucho menor a los plazos de prescripción establecidos por las leyes de fondo.

Los plazos de caducidad en el Derecho Administrativo, para muchos doctrinarios, deben reputarse inconstitucionales ${ }^{30}$, en cuanto cercenan el acceso a la jurisdicción, el derecho de propiedad y el derecho a una tutela judicial efectiva (arts. 17 y $18 \mathrm{CN}$ y arts. 8 y 25 del Pacto de San José de Costa Rica, de rango constitucional conforme el art. 75 inc. 22 de la $\mathrm{CN}$ ). De otra parte, la circunstancia de aceptar los plazos de caducidad como perentorios y fatales, implica, en nuestro derecho, atribuir a la función administrativa, una certeza y valor de cosa juzgada

\footnotetext{
30 Ver CASSAGNE, Juan Carlos, Acerca de la caducidad y prescripción de los plazos para demandar al Estado, ED, 45-285 y El plazo de caducidad del art. 25 de la ley 19.549 y su inaplicabilidad a los actos unilaterales vinculados a contratos administrativos, ED, 118-377; MAIRAL, Héctor A., op. cit., $T^{\circ}$ I, p. 380 y ss.; BIANCHI, Alberto B., ¿Tiene fundamentos constitucionales el agotamiento de la instancia administrativa?, LL 1995-A, 397; TAWIL, Guido S., Los plazos para accionar en la instancia contencioso administrativa: primera aproximación, Régimen de la Administración Pública, n 133, p. 11 y ss., Buenos Aires, 1989 y Administración y Justicia, T II, p. 178 y ss., ed. Depalma, Buenos Aires, 1993
} 
equivalente a la función judicial, alterando de ese modo, la interdicción prescripta en el art. 109 de la Constitución Nacional ${ }^{31}$.

\section{7. La cosa juzgada administrativa sólo limita la revocación de oficio de la Administración, no impide la impugnación y control judicial ulterior}

Del mismo modo, la autoridad de cosa juzgada que se le reconoce a los actos de homologación, ya sea por homologación de "acuerdos", o por el mero transcurso del tiempo ("silencio"), que regula el artículo 2 inc. "b" tercer párrafo, artículo 4 del Anexo I, y 46 de la ley 27.348; son inconstitucionales, y tiene serias objeciones.

Primero porque afectan el principio de irrenunciabilidad de derechos (artículo 12 Ley 20.744), y a su vez no puede ser admitido en un régimen que se precia de efectivizar prestaciones "irrenunciables" y de carácter "alimentario" (art. 11 ley 24.557). Segundo porque para los supuestos de silencio, ello no encuadra con lo normado por el artículo 15 de la ley 20.744, en tanto allí se tratan de "una justa composición de derechos e intereses", no siendo procedente por el mero transcurso del tiempo. Tercero, porque el supuesto de homologación que se establece en el Anexo I, sólo exige al Servicio de Homologación constatar "la libre emisión del consentimiento por parte del trabajador o de su derechohabiente", recordando que el libre ejercicio de la voluntad se encuentra restringido en el ámbito del Derecho del Trabajo, en tanto el mismo es nulo en cuanto sea para suprimir o reducir los derechos previstos en la ley, los estatutos profesionales, las convenciones colectivas o los contratos individuales, esto es, las homologaciones administrativas o judiciales, deben respetar el "orden público laboral", no la "libre emisión del consentimiento", por la sencilla razón que al Estado le debe interesar, y a su vez tiene responsabilidad internacional, de que se respeten los derechos humanos basales como son la vida,

31 Ver Juan Carlos Cassagne op cit 
salud y seguridad en el trabajo. Y cuarto, porque como bien lo señala Agustín Gordillo ${ }^{32}$, cuando expresa que "la cosa juzgada judicial y la cosa juzgada administrativa no tienen en común, como a primera vista podría parecer, ser ambas cosa juzgada; por el contrario, cosa juzgada en sentido estricto es sólo la que se produce respecto de las sentencia judiciales. Una sentencia judicial que hace cosa juzgada no es ya impugnable por recurso o acción alguna y no puede ser modificada por otro tribunal; la cosa juzgada administrativa en cambio implica tan sólo una limitación a que la misma administración revoque, modifique o sustituya el acto y no impide que el acto sea impugnado y eventualmente anulado en la justicia"; la cosa juzgada administrativa sólo limita la posibilidad de revocación del acto por la propia Administración, pero no impide su impugnación judicial, sino se estaría reconociendo a la administración la posibilidad de ejercer una función judicial que alteraría la interdicción del artículo 109 de la Constitución Nacional.

\section{III.8. La tesis de la subsanación y el carácter meramente revisor de la justicia}

Así llegamos a la denominada "tesis de la subsanación", que es la que le asigna a la justicia un mero carácter revisor de lo previamente actuado en sede administrativa. ${ }^{33}$

Esta tesis que por suerte ya ha sido superado por el Derecho Administrativo y la jurisprudencia de nuestro país, refiere a que "no interesa la indefensión sucedida en sede administrativa (prejudicial) si el interesado pudo defenderse ulteriormente ante la Justicia”.

\footnotetext{
32 Ver "Tratado de Derecho Administrativo" Tomo II, capítulo VII "Estabilidad e impugnación" Agustín Gordillo

33 Según refiere Fabián Omar Canda "Al analizar ciertos fallos de la Corte Supr. Que se ocuparon de la garantía de defensa en sede administrativa, Linares dio en llamar "tesis de la subsanación" a la postura observada por el Máximo Tribunal en punto a que no interesa la indefensión sucedida en sede prejudicial si el interesado pudo defenderse ante la Justicia" (Ver capítulo XII "El debido proceso adjetivo. La llamada "Teoría de la subsanación" en "Procedimiento Administrativo" Abeledo Perrot Guido Santiago Tawil, director)
} 
En el caso, no importaría la violación al derecho de defensa en juicio, ni la garantía del debido proceso en los trámites que se suceden ante las Comisiones Médicas, si con posterioridad el trabajador cuenta con un recurso judicial para revisar lo actuado.

La justicia meramente "revisora" o "subsanadora" de los vicios que pudieran haber ocurrido en sede administrativa, actualmente está seriamente cuestionada y dejada de lado. No es lo que se requiere como servicio de justicia en un país democrático, según los estándares del Sistema Interamericano de los Derechos Humanos.

Los sistemas judiciales de revisión de la actividad administrativa, dificultan la efectivización de los derechos humanos fundamentales y niegan la garantía del acceso a la justicia y la tutela judicial efectiva, según apunta Pablo Octavio Cabral ${ }^{34}$

\section{III.9. “Burghi” y la justicia residual}

Llamativamente cierto sector de la jurisprudencia a partir del fallo de la Sala II de la Cámara Nacional de Apelaciones del Trabajo, haciendo suyo un dictamen del por entonces Fiscal General Eduardo Álvarez en la causa "Burghi"35; sostiene la constitucionalidad de la ley 27.348, a partir de sustentar la tesis de la subsanación o meramente revisora de la justicia. Reservándole así a la Justicia un mero carácter secundario y residual, en la cual sólo se actúa para subsanar omisiones y siempre y cuando la Administración se lo permita.

Lamentablemente para los defensores de ésta tesis (de la convalidación o subsanación) tenemos malas noticias, en tanto actualmente ello se contradice con la reforma constitucional

\footnotetext{
34 Ver "Derecho administrativo" Carlos Alfredo Botassi (director) Pablo Octavio Cabral (coordinador), Editorial de la Universidad Nacional de La Plata, La Plata, 20017 y Cabral, Pablo Octavio "La justicia administrativa como herramienta para la efectivización de los derechos sociales reconocidos constitucionalmente en la provincia de Buenos Aires".

35 Sentencia del 3/058/2017 de la CNAT Sala II
} 
del año 1994, con algunos textos constitucionales como el de la Provincia de Buenos Aires, con la jurisprudencia de la CSJN y de la SCBA y con los fallos de la Corte IDH. De allí la inconsistencia de la argumentación expresada en la causa "Burghi" cuando refiere que "...la utilización de una instancia administrativa especializada con adecuado control y revisión judicial, ha sido admitida por la jurisprudencia, condicionándolas a la ulterior "revisión judicial suficiente". Claro que la jurisprudencia que invocan los jueces en "Burghi", se quedó en lo dicho por la Corte en 1960, en la causa "Fernández Arias", pero desde entonces ha pasado mucha agua por debajo del puente y esa postura es hoy insostenible jurídicamente.

\section{III.10. “Ángel Estrada”y los límites constitucionales a las facultades jurisdiccionales de la administración}

La Corte retomó nuevamente el debate sobre los tribunales administrativos y el ejercicio de facultades jurisdiccionales por entes administrativos, y si bien no los descalificó totalmente, les impuso nuevas restricciones ${ }^{36}$.

La doctrina de la Corte en el fallo Ángel Estrada y Cía. S.A. c. Secretaría de Energía y Puertos ${ }^{37}$, estableció los límites constitucionales de validez del otorgamiento de facultades jurisdiccionales a órganos administrativos que son: 1) que el objetivo económico y político tenido en cuenta por el legislador haya sido razonable, 2) que no sea cualquier controversia diferida a órganos administrativos, 3) que la independencia, imparcialidad y razonabilidad de aquellos deben estar aseguradas, y 4) mantuvo lo ya dicho en "Fernández Arias", en cuanto a que sus decisiones estén sujetas a un control judicial amplio y suficiente.

No nos detendremos a analizar particularmente si el procedimiento de la Resolución 298/2017 y las facultades jurisdiccionales ejercidas por las Comisiones Médicas, cumplen con

36 Ver "Las Comisiones Médicas Jurisdiccionales" Rubinzal - Culzoni Editores de Daniela Favier

37 Fallos Corte: 328:651 del 2005 
éstos 4 requisitos establecidos por la CSJN, ello ya ha sido desarrollado ampliamente por la doctrina especializada (como es el caso de Gialdino, Schick, Formaro, entre otros).

Sí nos adentraremos en lo apuntado por Formaro ${ }^{38}$, en cuanto critica que en "Burghi" no se hace ninguna alusión al procedimiento (res. 298/17 SRT). Si se está analizando la validez del sistema, esto es, la concreta mecánica que asume en el caso particular de este régimen la garantía de la defensa en juicio, esto debió haberse analizado.

Queremos detenernos puntualmente en este requisito no desarrollado tampoco expresamente por la CSJN en "Ángel Estrada" pero que sí surge de otros precedentes, como es, el respeto al "derecho de defensa y la garantía del debido proceso" en sede administrativa. Esto que se ha dado en llamar, la tutela administrativa efectiva ${ }^{39}$

\section{III.11. “Astorga Brach" y la tutela administrativa efectiva}

La pregunta que deberíamos formularnos a esta altura es ¿rige la garantía del debido proceso y la tutela administrativa efectiva en el ámbito del procedimiento administrativo, o para invocar ésta garantía debemos esperar al proceso judicial ulterior?

Esto que la doctrina ha dado en llamar la "tutela administrativa efectiva", fue incorporado expresamente en algunos textos constitucionales en 1994, como es el caso del de la Provincia de Buenos Aires, que en su artículo 15 expresamente reconoce "la inviolabilidad de la defensa de la persona y de los derechos en todo procedimiento administrativo o judicial".

\footnotetext{
38 Ver "Análisis de las sentencias de la CNAT sobre el control constitucional del procedimiento de la ley 27.348" Doctrina Laboral y Previsional - Errepar - № 389 - Enero/2018, p. 35 Juan J. Formaro

39 Ver "Alcances de la denominada tutela administrativa efectiva. Comentario al fallo de la Corte Suprema de Justicia de la Nación 'Astorga Bracht, Sergio y otro c/COMFER - Decreto № 310/98 s/ amparo Ley № 16.986", en Revista Digital, Res Pública Argentina, RAP, Buenos Aires, 16, junio de 2014 Nro.: 343 pp. 317-330 Canosa, Armando N.
} 
También fue incorporado vía artículo 75 inc. 22 de la Constitución Nacional, en relación a las convenciones internacionales de derechos humanos, que cuentan con jerarquía constitucional, en cuanto resguardan el derecho a la tutela administrativa y judicial efectiva (arts. XVIII y XXIV de la Declaración Americana de los Derechos y Deberes del Hombre, $8^{\circ}$ y 10 de la Declaración Universal de Derechos Humanos, $8^{\circ}$ y 25 de la Convención Americana sobre Derechos Humanos, $2^{\circ}$ inc. $3^{\circ}$ aps. a y b, y 14 inc. $1^{\circ}$ del Pacto Internacional de Derechos Civiles y Políticos).

¿Puede sostenerse jurídicamente una argumentación como la esbozada en "Burghi" en cuanto a que la instancia administrativa es válida en tanto esté condicionada a su ulterior revisión judicial? ¿Por qué la justicia debe esperar a un control ulterior, cuando los textos constitucionales y los tratados de derechos humanos nos mandan garantizar la tutela administrativa efectiva y continua?

La CSJN aludió por primera vez a la "tutela administrativa efectiva" en la causa "Astorga Bracht Sergio y otro v. Comfer -decreto 310/1998 s/ amparo ley 16.986" "40. Sostuvo allí que la disposición impugnada era violatoria del artículo 18 de la Constitución Nacional y de diversas normas contenidas en tratados internacionales de derechos humanos con jerarquía constitucional, "en cuanto resguardan el derecho a la tutela administrativa y judicial efectiva" ${ }^{41}$.

En éste caso, la corte cita la garantía del art. 18 de la Constitución Nacional y de las convenciones internacionales de derechos humanos, que cuentan con jerarquía constitucional, en cuanto resguardan el derecho a la tutela administrativa y judicial efectiva (arts. XVIII y XXIV de la Declaración Americana de los Derechos y Deberes del Hombre, $8^{\circ}$ y 10 de la Declaración Universal de Derechos Humanos, $8^{\circ}$ y 25 de la Convención

\footnotetext{
40 Fallos 327:4185 del 14/10/2004

41 Ver Diario Administrativo Nro 160 - 04.07.2017 "Tutela Administrativa Efectiva. Sus bases constitucionales y convencionales" Por Marisa Bibiana Caruso
} 
Americana sobre Derechos Humanos, $2^{\circ}$ inc. $3^{\circ}$ aps. a y b, y 14 inc. $1^{\circ}$ del Pacto Internacional de Derechos Civiles y Políticos).

Sostuvo que la garantía mencionada, que supone la posibilidad de ocurrir ante los tribunales de justicia -a lo que cabe agregar, ante las autoridades administrativas competentes- $y$ obtener de ellos sentencia o decisión útil relativa a los derechos de los particulares o litigantes (Fallos: 310:276 y 937; 311:208) y que requiere, por sobre todas las cosas, que no se prive a nadie arbitrariamente de la adecuada y oportuna tutela de los derechos que pudieren eventualmente asistirle sino por medio de un proceso -o procedimiento- conducido en legal forma y que concluya con el dictado de una sentencia -o decisiónfundada (Fallos: 310:1819).

Lo que reconoce la Corte a partir de éste fallo, es que la tutela administrativa efectiva debe existir, tanto en la etapa de formación de la decisión administrativa como en la faz impugnatoria y previa a la instancia judicial. Es decir, no se garantiza sólo el derecho al debido proceso con la existencia de un recurso judicial ulterior; sino que en los procedimientos administrativo, y mucho más en los que se ejercen facultades jurisdiccionales, se deben respetar las garantías del debido proceso.

En el fallo se consagra el derecho del particular a obtener un pronunciamiento en sede administrativa $\mathrm{y}$, por ende, en la obligación de la Administración de resolver por medio de decisiones -actos administrativos- dictada previo tránsito por un procedimiento administrativo conducido en legal forma (Art. $7^{\circ}$ inc. d) ley 19.549).

Esta jurisprudencia fue mantenida por la Corte pese a sus cambios de miembros, en tanto fue confirmado posteriormente en fallos como "Losicer" ${ }^{22}$, "Bonder Aaron” ${ }^{43}$ y también en "Cepis" ${ }^{44}$,

\footnotetext{
42 Causa "Losicer, Jorge Alberto y otros", Fallos: 335:1126 del 2012

43 Causa "Bonder Aaron", CSJN del 19/11/2013. Ver también "Garantías del debido proceso en procedimientos administrativos. Plazo razonable" por Lucía Magalí Rozenberg, portal Infojus

44 Causa "Centro de Estudios para la Promoción de la Igualdad y la Solidaridad y otros c/ Ministerio de Energía y Minería s/ amparo colectivo" (Expte. N FLP 8399/2016/CS1)
} 
cuando se anuló un procedimiento de fijación tarifaria, al no haberse respectado el procedimiento de audiencias públicas, método a través del cual se efectiviza el "derecho a ser oído" que reconoce el sistema interamericano ${ }^{45}$.

De modo que, el criterio de convalidar cualquier procedimiento administrativo, con la única condición de garantizarse un recurso judicial ulterior suficiente sostenido a partir de "Fernández Arias c/ Poggio", al cual se suscribe totalmente a destiempo en "Burghi", no forma parte de la jurisprudencia vigente de la CSJN, contradice los textos constitucionales y los tratados de Derechos Humanos.

Además de la jurisprudencia de la Corte, es doctrina legal de la SCBA, en cuanto a que "las instancias administrativas deben respetar los mismos principios que las instancias judiciales (derecho de defensa)" " la "tutela judicial continua y efectiva y la inviolabilidad de la defensa de la persona y de los derechos en todo procedimiento administrativo y judicial" ${ }^{47}$. Para ser categórica al decir que "circunscribir el análisis de la impugnación de los actos que dictan los colegios profesionales a su "legalidad", sin permitir al afectado plantear una amplia revisión de los hechos en los que se basan, se halla en pugna con principios y garantías de primer orden, como son el acceso irrestricto a la justicia, la tutela judicial efectiva y la inviolabilidad de la defensa en juicio" ${ }^{48}$.

\section{La ley de procedimientos administrativos, la ley de riesgos del trabajo y el debido proceso}

La ley 19.549, que regula en el ámbito nacional el procedimiento administrativo, expresamente reconoce las garantías

\footnotetext{
45 Ver al respecto "Audiencias públicas y debido proceso administrativo. Algunas reflexiones sobre el fallo “CEPIS" por Mauricio Goldfarb en ED No 14.037 Año LIV 12/09/2016

46 Causa SCBA "Fiscalía de Estado c/Capra” del 2013

47 Causas SCBA "Bymo" 1996, "Alvarez" 2013, “Cepeda" 2015 y “Gómez" 2016 entre otras

48 Causa SCBA “Colegio de Bioquímicos" del 2008
} 
del debido proceso en todo procedimiento administrativo. Que comprenden: a) el derecho a ser oído, que quiere decir el derecho de exponer las razones de sus pretensiones y defensas antes de la emisión de actos que se refieren a sus derechos subjetivos $o$ intereses legítimos, interponer recursos y hacerse patrocinar y representar profesionalmente. Cuando una norma expresa permita que la representación en sede administrativa se ejerza por quienes no sean profesionales del Derecho, el patrocinio letrado será obligatorio en los casos en que se planteen o debatan cuestiones jurídicas. B) el derecho a ofrecer y producir pruebas, que significa el derecho de ofrecer prueba y que ella se produzca, si fuere pertinente, debiendo la administración requerir y producir los informes y dictámenes necesarios para el esclarecimiento de los hechos todo con el contralor de los interesados y sus profesionales, quienes podrán presentar alegatos y descargos una vez concluido el período probatorio. c) el derecho a una decisión fundada, que implica que el acto decisorio haga expresa consideración de los principales argumentos y de las cuestiones propuestas, en tanto fueren conducentes a la solución del caso.

La ley 24.557 menciona solo dos veces la garantía del "debido proceso", lo hace en su artículo 21 inc. "5" cuando establece que: "En lo que respecta específicamente a la determinación de la naturaleza laboral del accidente prevista en el inciso a) del apartado 1 de este artículo y siempre que al iniciarse el trámite quedare planteada la divergencia sobre dicho aspecto, la Comisión actuante, garantizando el debido proceso, deberá requerir, conforme se establezca por vía reglamentaria, un dictamen jurídico previo para expedirse sobre dicha cuestión. (Apartado incorporado por art. 11 del Decreto 1278/2000). También lo menciona en el procedimiento de enfermedades no listadas, cuando expresa en el artículo 6 inc. 2. B) II cuando expresa que "La Comisión Médica Jurisdiccional sustanciará la petición con la audiencia del o de los interesados así como del empleador y la ART; garantizando el debido proceso, producirá las medidas de prueba necesarias y emitirá resolución debidamente fundada en peritajes de rigor científico." (El subrayado me pertenece). 
La ley 27.348 no menciona a la garantía del debido proceso en todo su articulado, y la Resolución 298/2017 sólo lo hace en su exposición de motivos y en el artículo 36 cuando establecen el patrocinio letrado obligatorio, a los fines de garantizar "el debido proceso legal".

Es decir, sin perjuicio del escaso espacio que se le da a la garantía del debido proceso en la regulación de los trámites administrativos ante Comisiones Médicas, lo cierto es que para la ley 27.348 y su reglamentación, es un requisito que se debe garantizar en instancia de Comisiones Médicas, por lo cual no puede escapar a nuestro análisis si se cumple con dicha garantía en dicha instancia procedimental administrativa.

\section{La tutela administrativa y el debido proceso según el Sistema Interamericano de Derechos Humanos}

Además de los arts. XVIII y XXIV de la Declaración Americana de los Derechos y Deberes del Hombre, $8^{\circ}$ y 10 de la Declaración Universal de Derechos Humanos, y del 14 inc. $1^{\circ}$ del Pacto Internacional de Derechos Civiles y Políticos, son pilares centrales los artículos $8^{\circ}$ y 25 de la Convención Americana de los Derechos Humanos.

Los arts. $8^{\circ}$ y 25 de la CADH consagran las garantías mínimas del debido proceso. El citado art. 8 titulado "Garantías Procesales" establece que " 1 . Toda persona tiene derecho a ser oída, con las debidas garantías y dentro de un plazo razonable, por un juez o tribunal competente, independiente e imparcial, establecido con anterioridad por la ley, en la sustanciación de cualquier acusación penal formulada contra ella, o para la determinación de sus derechos y obligaciones de orden civil, laboral, fiscal o de cualquier otro carácter.”

Por su parte, el art. 25 -nominado "Protección Judicial" prevé que " 1 . Toda persona tiene derecho a un recurso sencillo y rápido o a cualquier otro recurso efectivo ante los jueces o tribunales competentes, que la ampare contra actos que violen sus derechos fundamentales reconocidos por la Constitución, 
la ley o la presente Convención, aun cuando tal violación sea cometida por personas que actúen en ejercicio de sus funciones oficiales. 2. Los Estados Partes se comprometen: a) a garantizar que la autoridad competente prevista por el sistema legal del Estado decidirá sobre los derechos de toda persona que interponga tal recurso; b) a desarrollar las posibilidades de recurso judicial, y c) a garantizar el cumplimiento, por las autoridades competentes, de toda decisión en que se haya estimado procedente el recurso."

La CIDH se ha pronunciado sosteniendo que los arts. $8^{\circ} \mathrm{y}$ 25 de la CADH consagran las garantías mínimas del debido proceso, entendido éste como "el conjunto de requisitos que deben observarse en las instancias procesales, cualquiera que ellas sean, a efecto de que las personas puedan defenderse adecuadamente ante cualquier acto emanado del estado que pueda afectar sus derechos". En efecto, "se exige que cualquier autoridad pública, sea administrativa, legislativa o judicial, cuyas decisiones puedan afectar los derechos de las personas, adopte tales decisiones con pleno respeto de las garantías del debido proceso legal". Es decir, el sistema interamericano no se ciñe al principio "judicialista" sólo exige que cualquiera sea el organismo del Estado que ejerza funciones jurisdiccionales, debe respetarse la garantía del debido proceso.

De ello se desprende que los Estados, deben asegurar el respeto de estas garantías del debido proceso reconocidas en la $\mathrm{CADH}$ en los distintos procedimientos en que cualquier órgano estatal, ya sea administrativo, legislativo o judicial, dicte decisiones sobre la determinación de los derechos y obligaciones de las personas. ${ }^{49}$ Con lo cual, el procedimiento administrativo ante las Comisiones Médicas, debe respetar la garantía de la tutela administrativa efectiva, con los alcances que le reconoce la Corte IDH.

49 Ver al respecto "Caso del Tribunal Constitucional vs. Perú. Competencia", sentencia del 31/1/2001, párr. 55; "Caso Baena Ricardo y otros vs. Panamá", sentencia del 2/2/2001, párr. 124; "Caso Ivcher Bronstein vs. Perú. Fondo, Reparaciones y Costas", sentencia del 6/2/2001, párr. 102; entre otros 


\title{
V.1. ¿Qué garantías de la tutela administrativa efectiva y del debido proceso son aplicables al procedimiento administrativo de las Comisiones Médicas?
}

\author{
Siguiendo a Pablo R. Toledo ${ }^{50}$, el Sistema Interamericano \\ tiene garantías que son aplicables a todo tipo de proceso o pro- \\ cedimiento (penal, civil, fiscal, laboral, etc.), como son las de los \\ artículos $8.1^{51}$ y $25^{52}$; y otras que son más bien de tipo penal y \\ están reguladas para supuestos de "inculpación de un delito", \\ como lo son las del artículo $8.2^{53}$.
}

50 Ver "El proceso judicial según los estándares del Sistema Interamericano de Derechos Humanos" Ad-HOC. Ver también "Administración Pública, Juridicidad y Derechos Humanos, Abeledo Perrot, de Pablo Ángel Gutiérrez Colantuono

51 El artículo 8. Garantías Judiciales. Dice en su inciso 1: Toda persona tiene derecho a ser oída, con las debidas garantías y dentro de un plazo razonable por un juez o tribunal competente, independiente e imparcial, establecido con anterioridad por la ley, en la sustanciación de cualquier acusación penal formulada contra ella o para la determinación de sus derechos y obligaciones de orden civil, laboral, fiscal o de cualquier otro carácter.

52 El artículo 25. Protección Judicial dice: 1. Toda persona tiene derecho a un recurso sencillo y rápido o a cualquier otro recurso efectivo ante los jueces o tribunales competentes, que la ampare contra actos violen sus derechos fundamentales reconocidos por la Constitución, la ley o la presente Convención, aun cuando tal violación sea cometida por personas que actúen en ejercicio de sus funciones oficiales.- 2. Los Estados Partes se comprometen: a) a garantizar que la autoridad competente prevista por el sistema legal del Estado decidirá sobre los derechos de toda persona que interponga el recurso; b) a desarrollar las posibilidades de recurso judicial, c) a garantizar el cumplimiento, por las autoridades competentes, de toda decisión en que se haya estimado procedente el recurso.

53 El artículo 8. Garantías Judiciales. Dice en su inciso 2. Toda persona inculpada de delito tiene derecho a que se presuma su inocencia mientras no se establezca legalmente su culpabilidad. Durante el proceso, toda persona tiene derecho, en plena igualdad, a las siguientes garantías mínimas: a) derecho del inculpado de ser asistido gratuitamente por el traductor 0 intérprete si no comprende o no habla el idioma del juzgado o tribunal; b) comunicación previa y detallada al inculpado de la acusación formulada; c) concesión al inculpado del tiempo y de los medios adecuados para la preparación de su defensa; d) derecho del inculpado de defenderse personalmente o de ser asistido por un defensor de su elección y de comunicarse libre y privadamente con su defensor; e) derecho irrenunciable de ser asistido por un defensor proporcionado por el Estado, remunerado o no según la legislación interna si el inculpado no se defendiere por si mismo ni nombrase defensor dentro del plazo establecido por la ley; f) derecho de la defensa de interrogar a los testigos presentes en el tribunal y de obtener la comparecencia, como testigos o peritos de todas personas que puedan arrojar luz sobre los hechos; g) derecho a no ser obligado a declarar contra sí mismo ni a declararse culpable, y h) derecho de recurrir del fallo ante juez o tribunal superior. 
Ahora bien, a partir de la interpretación muy activa de la Corte IDH, muchas de las garantías de tipo penal que establece el artículo 8.2, se consideran extensibles para ser aplicadas a todo tipo de procesos o procedimientos, incluidos los no penales, pero se deben analizar bien las garantías en tanto por querer extender una garantía que es reconocida exclusivamente a personas humanos, podemos terminar favoreciendo a otros sujetos no especialmente protegidos en otras ramas del derecho y así vulnerar otros derechos fundantes de dicha rama. Como sería por ejemplo, al garantizar la "doble instancia" con recursos con efectos suspensivos, a una aseguradora de riesgos del trabajo, en tanto la garantía procesal va a ser utilizada más bien como dilación en el pago de las prestaciones, que en la búsqueda de la aplicación efectiva del derecho que le asiste.

En ése sentido ¿cuáles serían las garantías que podemos invocar, que resultan aplicables al procedimiento ante Comisiones Médicas regulados por la Resolución 298/2017?

a) Derecho a ser oído con las debidas garantías (principio de igualdad procesal o igualdad de armas, bilateralidad y contradicción, y resolución motivada) (art. 8.1 y $225 \mathrm{CADH}$ ); b) Derecho a obtener una resolución en un plazo razonable (art. 8.1 CADH); c) Derecho a recurrir ante un juez o tribunal competente; d) independiente e imparcial (art. 8.1 CADH); e) Derecho a contar con el tiempo y los medios adecuados para la preparación de la defensa (art. 8.2 inc. "c" CADH); f) Derecho de defenderse personalmente y a ser asistido por un defensor de su elección (art. 8.2 inc. "d" y "e" CADH); g) Derecho de ofrecer y producir pruebas (art. 8.2 inc. "f" CADH); h) Derecho de no declarar contra sí mismo (art. 8.2 inc. "g" CADH); i) Derecho de recurrir la decisión (art. 8.2 inc. "h" $\mathrm{CADH}$ ) 


\section{V.2. Algunas violaciones a la tutela administrativa efectiva y al debido proceso que se producen en el trámite ante las Comisiones Médicas}

Son muchas las violaciones en las que se incurre en el procedimiento que debe seguir obligatoriamente un trabajador accidentado o enfermo por causas laborales, antes de poder acceder a la justicia.

No voy analizar aquí las violaciones al artículo 99 inc. 2 de la Constitución Nacional, en cuanto se ejercita el poder reglamentaria por normas de menor jerarquía que los Decretos del Poder Ejecutivo; ni la asunción de facultades ni delegaciones en cuanto a creación de comisiones médicas, reasignación de competencias y modificaciones al procedimiento que se realizan mediantes normas de menor rango, en muchos casos modificando leyes o decretos; la asignación de "superpoderes" al Superintendente de Riesgos del Trabajo; ni las adhesiones provinciales al régimen nacional, en cuanto requiere la delegación expresa a la jurisdicción administrativa nacional de poderes propios que se encuentran impedidos de ser otorgados sin previa reforma constitucional; ni la imparcialidad e independencia de los órganos que ejercen facultades jurisdiccionales, en el caso las Comisiones Médicas; siendo ellos, todos puntos suficientemente abordados por la doctrina especializada.

Trataré de enfocarme sobre el resto de las garantías del debido proceso, que rigen en todo procedimiento administrativo, y que a nuestro criterio son inobservadas en el procedimiento regulado por la Resolución 298/2017.

a) El derecho a ser oído con las debidas garantías. Se trata de un derecho básico que consiste en el derecho de exponer la pretensión y de ser escuchado, antes de la emisión del acto administrativo que pone fin al procedimiento. Por ejemplo en el caso de las Comisiones Médicas, sería nulo un dictamen médico que se emitió, sin antes dar oportunidad de ser oído el trabajador. En el diseño de la Resolución 298/2017, por ejemplo en el procedimiento de "Determinación de la incapacidad" 
(art. $\left.4^{\circ}\right)$ no se contempla oportunidad procesal de presentación alguna para el trabajador, ya que la presentación sólo la hace la ART o empleador autoasegurado, no se prevé posibilidad de traslado, sólo se cita al trabajador a la audiencia, y lo único que se le permite en ejercicio de este derecho, es optar sobre la competencia de la Comisión Médica (art. 5) y ofrecer prueba (art. 7). Esta omisión no queda subsanada con el derecho de presentar el alegato (art. 8) en tanto este sólo refiere a hacer mérito sobre la prueba ofrecida y no se equipara a una exposición de la pretensión y una defensa de la misma. Se vulnera ésta garantía, cuando la comisión médica se niega a recepcionar presentaciones por escrito, porque no se adecúan a sus normas reglamentarias, o cuando exige para la presentación de los mismos con el abogado en forma presencial, cuando el letrado puede firmar la presentación y no es necesario que se encuentre presente al momento de su inicio, mientras la ART puede enviarlo por ventanilla electrónica. Hay que recordar que en todo procedimiento administrativo rige el principio de informalismo en favor del peticionante, que tiende a garantizar que las peticiones articuladas por particulares en sede administrativa no serán obstaculizadas por defectos de índole formal. Este principio se encuentra expresamente contemplado en el artículo $1^{\circ}$ inc. "c" de la ley 19.549. En estos puntos el procedimiento administrativo podría ser impugnado por inconstitucional por omisión de un requisito esencial de ser oído, lo que en modo alguno podría subsanarse con el recurso judicial ulterior.

b) El derecho a ser oído, comprende también el derecho de igualdad procesal o de armas, que no implica que la administración sea un "árbitro" imparcial que al final convalida el resultado. Sino que se encuentra obligado a impulsar el procedimiento y remover los obstáculos que cada una de las partes tengan durante el curso del mismo, para lograr la tan ansiada igualdad procesal. En el caso del procedimiento ante Comisiones Médicas, la desigualdad entre las partes es notoria, por ejemplo, mientras una parte se encuentra adherida al sistema de ventanilla electrónica (ART) y puede compulsar 
todo el expediente, la otra no (trabajador) y no puede tomar vista ni controlar los estudios ni las pruebas que se incorporan. Esto es de suma gravedad porque también vulnera el principio de bilateralidad y contradicción del procedimiento. En todos los procedimientos administrativos ante las Comisiones Médicas, existe esta desigualdad procedimental manifiesta. Lo que se suma a la desigualdad ontológica, como lo expresa María Paula Lozano ${ }^{54}$, la que se expresa en la relación laboral que se profundiza ante el infortunio del trabajo, ya que es la parte más débil -el trabajador- quien sufre una minusvalía en su integridad psicofísica, con lo cual dicha asimetría estructural se traslada -agravándose- a la relación que debe mantener con la aseguradora de riesgos del trabajo.

c) El derecho a ser oído también comprende el derecho a obtener una resolución motivada. Nuestra forma republicada de gobierno y el correcto ejercicio del derecho de defensa, nos obligan a motivar (fundamentar) los actos administrativos. Esto es una exigencia que imponen todas las leyes de procedimiento y fue un requisito exigido en los fallos de la CSJN resaltados supra. Este es un tema que pocos se han detenido, pero tanto la ley nacional 19.549 (art. 7 inc. "e"), como la ley provincial 7647 (art. 108), establecen como requisito esencial la motivación del acto administrativo. En el caso del procedimiento de la Resolución 298/2017, no establece éste requisito ni para los dictámenes, ni para los actos del titular del Servicio de Homologación. Los únicos requisitos que establece la norma son los de "notificación" a los interesados y la constatación de la "libre emisión del consentimiento".

d) El derecho a ofrecer y producir pruebas es fundamental para el ejercicio del derecho de defensa. Si bien las Comisiones Médicas prevén la posibilidad de ofrecer prueba desde la primera presentación y hasta la fecha de la audiencia

54 Ver "Reforma de la Ley de Riesgos del Trabajo: veinte años no es nada. Volver a las inconstitucionales comisiones médicas" Revista de Derecho Laboral 2017 - 1 Actualidad Rubinzal - Culzoni. María Paula Lozano 
(art. 7) lo cierto es que es limitado el ofrecimiento de prueba. Por ejemplo no hay medios para ofrecer ni producir prueba pericial en higiene y seguridad, no se establecen las reglas de la producción de la prueba, como por ejemplo como se va a interrogar a un testigo, cuáles son los testigos excluidos, etc.

e) El derecho a obtener una resolución en un plazo razonable, es una garantía que en su momento se resaltó como positiva en relación a los tiempos que tiene actualmente la resolución de un caso en la justicia. Ahora bien, el breve plazo de 60 días prorrogables por 30 días más, no podría traer problemas. Con lo cual esta garantía se cumpliría. Pero con la puesta en marcha de la totalidad del sistema, incluida nuevas adhesiones provinciales, vemos que los plazos perentorios no se están cumpliendo, por lo cual se puede invocar la violación de ésta garantía (al plazo razonable) ante dicho incumplimiento, agotando así la vía y accediendo a la justicia.

f) Derecho a recurrir ante un juez o tribunal competente, independiente e imparcial. Sin extendernos demasiado, en tanto éste tema ya fue suficientemente abordado por la doctrina $^{55}$, lo cierto es que las Comisiones Médicas, forman parte de la administración activa, por lo cual no tienen independencia ni imparcialidad suficiente con uno de los poderes del Estado (Poder Ejecutivo) el que tiene vedada la actuación jurisdiccional. También es relevante el hecho de la financiación, en tanto una de las partes en conflicto financia la casi totalidad de las Comisiones Médicas. Lo cual demuestra su falta de imparcialidad. A su vez los integrantes de la Comisión Médica, carecen de la garantía de estabilidad en sus cargos, lo que es otro elemento que conspira contra su falta de imparcialidad. Para el sistema interamericano, el órgano competente, no necesariamente debe ser "judicial”, pero sí debe tener como requisito sine qua non, ser independiente e imparcial.

55 Ver "Breves apuntes sobre algunas inconstitucionalidades de la ley 27.348. Delegación de facultades provinciales reservadas Comisiones Médicas y Comisión Médica Central" material inédito que resume exposición en el Senado Provincial La Plata 23/08/2017 por Rolando Gialdino. 
g) Derecho a contar con el tiempo y los medios adecuados para la preparación de la defensa, esta si bien es una garantía penal, es extensible a cualquier tipo de procedimiento. En el caso de las Comisiones Médicas, se vislumbra claramente la falta de tiempo con cuentan los trabajadores para ensayar estrategias para su defensa. Véase a modo de ejemplo que el recurso judicial según el artículo 16 de la Resolución 297/2017 es de sólo 15 días.

h) Derecho de defenderse personalmente y a ser asistido por un defensor de su elección, que también es una garantía penal que resulta extensible a otras materias. Es una garantía fundamental para el correcto ejercicio de la técnica de la defensa. En el caso de las Comisiones Médicas, se exige el patrocinio letrado. Y cuando el trabajador no cuenta, se le suministra uno en sede de la Comisión Médica, el que se desconoce cuál su versación y capacitación, en muchas Comisiones Médicas hay sólo un letrado disponible, por lo que las posibilidades de elección se reducen mucho para los trabajadores. Este es un tema muy delicado, en cual muchos abogados, más que ejercer una acción de control y asesoramiento, simplemente acompañan a los trabajadores, para que arreglen "a lo que dé", por lo que los abogados pueden ser un instrumento para el asesoramiento, o meros acompañantes para convalidad todo lo actuado en sede administrativa, y así impedir el contralor judicial.

i) El Derecho de no declarar contra sí mismo es una garantía penal que es válidamente extensible al procedimiento por otras materias, como lo es ante Comisiones Médicas. Acá vemos que muchas "anamnesis", que son el conjunto de datos, que recabados por el médico en la audiencia de revisación, terminan siendo los elementos centrales de fundamentación del dictamen. Esto vulnera las garantías constitucionales.

j) El derecho de recurrir la decisión (art. 8.2 inc. "h" $\mathrm{CADH}$ ). Acá hay algunos cuestionamientos, sobre quiénes pueden invocar la garantía. Por ejemplo es sólo una garantía para personas humanas, no para sociedades, con lo cual las 
ARTs no la pueden invocar, como recurso para la dilación en el procedimiento.

\section{Colofón}

En el procedimiento administrativo establecido por la ley 27.348 y su reglamentación efectuada mediante Resolución 298/2017, no se respetan las garantías mínimas del debido proceso, ni el derecho de defensa. Razón por la cual, al ser ésta una vulneración grave, en tanto las normas reconocen, que la tutela administrativa efectiva es un derecho fundamental exigible en el ámbito de los procesos administrativos, máxime cuando ejercen funciones jurisdiccionales; ante la violación de estas garantías, se configuraría una tacha de nulidad en el procedimiento, que no puede esperar a ser impugnado o subsanado con el control judicial ulterior, sino que debería permitirse la asunción del control judicial en forma inmediata y sin dilaciones.

No nos oponemos a la existencia de procedimientos administrativos, es más, la complejidad actual de la cuestión, amerita que el Estado arbitre los mecanismos necesarios para la efectivización de los derechos. Sabemos que el proceso judicial sólo da respuestas a una porción menor de afectados en sus derechos por accidentes y enfermedades del trabajo, por lo cual el procedimiento administrativo con garantía plena del debido proceso, mientras que no se constituya en un obstáculo para el ejercicio de otros derechos fundamentales, podría ser una contribución importante, cuando no, un cumplimiento de una obligación convencional del Estado, que en última instancia es, la de garantizar el acceso a la jurisdicción y la realización de la justicia. 